\section{TRABALHO EM GRUPOS E AUTONOMIA COMO INSTRUMENTOS DA COMPETIÇÃO}

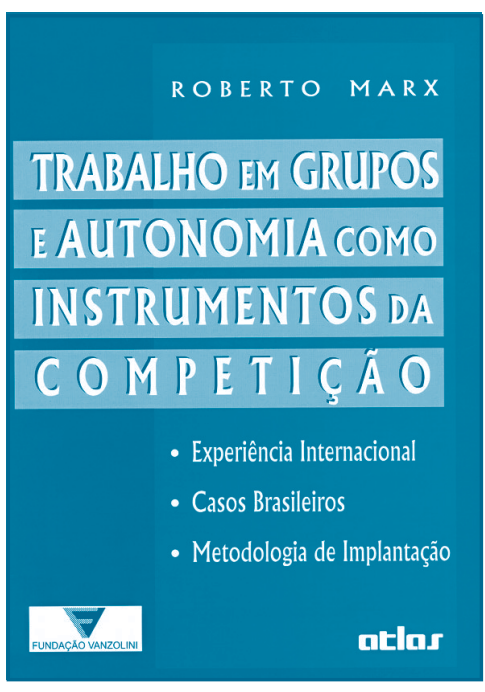

de Roberto Marx

São Paulo: Atlas, 1998, 168 p.

por Glauco Arbix, professor do Departamento de Sociologia da USP.

E-mail: garbix@usp.br

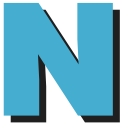
ão há mágica nem receita fácil. Tampouco há garantia de sucesso. Mesmo assim a indústria brasileira começou a discutir a conveniência dos grupos semi-autônomos como instrumentos emuladores do desempenho operacional. As experiências no Brasil, ainda que raras, sugerem que certas mudanças organizacionais que se baseiam na redistribuição do poder decisório no chão de fábrica, ampliando a autonomia das equipes de trabalhadores, podem ser eficazes, produtivas e mais democráticas a um só tempo. Mais do que isso, o funcionamento efetivo dos grupos semi-autônomos em alguns ramos da nossa indústria se aproxima bastante de experiências bem-sucedidas em países com padrões produtivos muito mais avançados do que o brasileiro.

Essa é uma das conclusões a que chegou Roberto Marx, em seu livro Trabalho em grupos e autonomia como instrumentos da competição, recém-lançado pela editora Atlas. Originalmente uma tese de doutorado pela Escola Politécnica da USP, essa obra carrega uma dupla marca: a da formação multidisciplinar que se desenvolve no Departamento de Engenharia de Produção - do qual Marx também é professor - e a das pesquisas de campo na Suécia, em fábricas da Volvo.

Mesclando abordagens da engenharia com as da administração de empresas, a sociologia do trabalho com a ergonomia, Marx elaborou uma das primeiras tentativas de sistematização, classificação e avaliação das iniciativas de implantação de trabalho em grupo e sua relação com autonomia e competitividade na indústria de hoje.

Sem mistificações, o livro procura mostrar como essa etiqueta - trabalho em equipe - é compreendida das mais diferentes maneiras no meio empresarial, servindo simultaneamente aos mais variados propósitos. Na verdade, um número expressivo de conceitos e preconceitos distintos sobre autonomia, confiança, responsabilidade, processo, participação e democracia esconde-se sob sua difusão pela imprensa, pelos departamentos de marketing das empresas e pelos gurus do modern management.

Exatamente por conhecer os meandros dessa discussão, Marx arregaçou as mangas e discutiu o significado dessas experiências para a indústria e para a economia. Trata-se, portanto, de pesquisa séria, que merece ser lida por quem busca orientação diante do emaranhado de concepções que procuram se diferenciar - camuflando - ou superar - inovando - os velhos métodos tayloristas da produção em massa.

O mundo industrial, como o da política, é recheado de lendas e mitologias. Precisamente por isso, tornase difícil o debate sobre sua trajetória, mesmo nas universidades. Distinguir e ordenar as mudanças é tarefa básica nos tempos modernos, principalmente quando sabemos que a formação de novos modelos está intimamente ligada à compreensão, aos interesses e ao jogo da economia política, no qual estão imersos seus designers.

Esse é um dos motivos pelos quais as inovações na organização do trabalho e da produção, basicamente as desenvolvidas pelo Grupo Volvo em Uddevalla (Sué- 
cia) a partir de 1989, continuam engasgadas na garganta dos defensores incondicionais da lean production (produção enxuta), com origens na Toyota (Japão). Os métodos que se inspiraram no "toyotismo" vêm sendo apresentados desde o início dos anos 90 não somente como os mais seguros e eficientes para o crescimento da produtividade, mas também como os únicos capazes de garantir o sucesso industrial a partir deste final de século.

Se em âmbito mundial a discussão de alternativas à produção enxuta sofreria a depreciação da moda, no Brasil seria desenvolvida apenas homeopaticamente e em pequenos círculos de especialistas. Compreensível, claro. O atraso e o preconceito do empresariado brasileiro, a tutela do Estado sobre as relações industriais e o distanciamento tácito do sindicalismo das discussões sobre o trabalho dentro das fábricas - visto como o reino das empresas - vêm contribuindo há décadas para dificultar a implantação de formas minimamente civilizadas e não-autoritárias na organização da produção.

Se nos lembrarmos do percurso histórico da nossa maltratada democracia, fica ainda mais fácil entender por que as iniciativas mais participativas sempre transitaram entre a fugacidade e a retórica, reproduzindo um cotidiano fabril sempre estreitamente vigiado. Exatamente por isso, esse livro de Marx assume importância especial ao trabalhar com as referências da Volvo no Brasil. Estas, no mínimo, ao estimular nossa reflexão, ofuscam a produção enxuta como o "the one best way", uma espécie de caminho natural - e superior - a ser trilhado na busca da competitividade.

A perspectiva dos grupos semi-autônomos nos convida, por um lado, a pensar sobre a necessária invenção de novas formas de organização do trabalho, capazes de integrar a busca da eficácia sem a rotinização estafante, o distanciamento daquele que produz, a indiferença, as doenças profissionais e o sofrimento. Por outro lado, leva-nos a refletir sobre as relações entre modernidade e cidadania: em geral, o desenvolvimento econômico dos países avançados em que esses grupos se configuraram baseou-se em fortes pactos entre capital e trabalho, incluindo um sindicalismo sólido, ligado a governos social-democratas. Fábrica e sociedade estiveram imersas em um ambiente de estímulo político à sintonia entre as democracias social e industrial.

Nos tempos bicudos de hoje, quando a democracia social parece estar fora de moda, todo pragmatismo tem sido pouco para abafar as possibilidades de uma reflexão séria sobre como superar o taylorismo/fordismo ou, como Marx prefere denominar, a escola clássica -, que ainda grassa pelo mundo afora. A conversão declarada de muitos conglomerados norte-americanos e europeus aos chamados "métodos japoneses" também contribuiu para pasteurizar desse debate.
Afinal, quem não gostaria de beber dos ensinamentos da Toyota, da Sony, da Honda ou de dezenas de outras empresas de sucesso, diante da verdadeira avalanche de produtos japoneses que passaram a devorar os mercados da Europa e dos Estados Unidos, expondo, num dado momento, as ineficiências da indústria ocidental? Mais ainda: quem não gostaria de absorver a superioridade industrial do país do sol nascente, berço da lean production, que atingiu o coração dos mercados mais exigentes com produtos mais modernos, baratos, práticos e de melhor qualidade?

Para difundir as novas descobertas orientais, uma enorme pesquisa sobre o insucesso da indústria automobilística americana - e sobre o alto desempenho da indústria japonesa - seria desenvolvida pelo Massachusetts Institute of Technology (MIT), através de um programa denominado International Motor Vehicle Program (IMVP), cujos resultados geraram um dos livros de maior sucesso do início dos anos 90: $A$ máquina que mudou o mundo, de J. Womack, D. Jones e D. Roos. Aparentemente, o livro consiste em um tratado sobre o universo dos carros e sua trajetória de constante racionalização e aperfeiçoamento produtivo. De fato, trata-se de uma reinterpretação do desenvolvimento industrial nos últimos cem anos, estruturada de modo a vaticinar o predomínio da lean production no próximo século: "acreditamos que, no final, a produção enxuta vá suplantar tanto a produção em massa como os últimos baluartes da produção artesanal em todas as áreas do esforço industrial, para se tornar o padrão universal de sistema de produção no século XXI".

Segundo os autores, a superioridade da produção enxuta sobre outras formas de produção industrial era tão revolucionária quanto evidente. A produção enxuta solicitava apenas a: "metade do esforço dos operários na fábrica, metade do espaço para fabricação, metade do investimento em ferramentas, metade das horas de planejamento para desenvolver novos produtos em metade do tempo".

Um dos milagres dessa nova forma de produzir estaria baseado na síntese inovadora entre a produção em massa e a artesanal, afugentando a rigidez da primeira e os altos custos da segunda. Assim, a produção enxuta empregaria: “(...) equipes de trabalhadores multiqualificados em todos os níveis da organização, além de máquinas altamente flexíveis e cada vez mais automatizadas, para produzir imensos volumes de produtos de ampla variedade".

Equipes de trabalhadores polivalentes ocupariam um lugar de destaque nas prescrições do livro. Os novos conceitos de work teams, ao lado de outros como o just in time, kanban e kaizen, passaram a freqüentar o noticiário especializado e as páginas da mídia. As corporações procuravam apresentar-se, então, como lean. Ou, 
pelo menos, dispostas a implantar o regime de excelência. E, depois de anos rejeitando a inteligência dentro da fábrica, diziam-se ávidas por valorizar o conhecimento, a qualificação, a iniciativa e a autonomia do trabalhador. Como explicar essas mudanças de comportamento?

O livro de Marx sugere que a flexibilidade e a autonomia começaram a ser vislumbradas "como parte integrante de um projeto empresarial (e não mais como resultado de pressões sociais como nos anos 70 e 80) em busca de competitividade e desempenho".

Aqui estamos no coração de uma das discussões mais importantes que têm marcado as pesquisas sobre as transformações do mundo do trabalho na década de 90 . $\mathrm{E}$, neste ponto, Marx poderia ter ido além dos muros da fábrica e discutido as tensões que vêm percorrendo a economia dos países avançados desde o final do ciclo virtuoso do pós-guerra. Sem a abordagem desses novos dilemas, as explicações sobre as mudanças na produção industrial correm o risco de adaptar-se, pragmaticamente, ao binômio competitividade/produtividade.

Em sua tentativa de classificar os diferentes tipos de trabalho em grupos no Brasil, Marx constatou como as equipes inspiradas no modelo Toyota mesclavam inovações com vários sustentáculos da escola clássica fordista, como "a idéia de gestão de postos de trabalho, com ênfase no indivíduo, na tarefa individual e na flexibilidade de alocação de trabalhadores pelos postos de trabalho do grupo".

Pesquisas em vários países mostram que as alterações introduzidas pela lean production na linha de montagem estão em muito pautadas pela natureza de sua organização em equipe, apresentada como uma estrutura de produção supostamente voltada para a recuperação e a reutilização do conhecimento do operário, que, coletivamente, poderiam definir os recursos, as trajetórias, o ritmo, os instrumentos e as metas no interior das empresas. Essa forma de organização da produção, centrada no trabalho, permitiria que compreendêssemos melhor a afirmação de Womack, Jones \& Roos de que a produção enxuta tornaria "o trabalho cada vez mais estimulante". Ou seja, o massacre cotidiano do trabalho fabril na produção em massa - pulverizado, intenso, prescrito e absolutamente controlado - estaria dando passos para sua transformação em trabalho mais reflexivo, qualificado e integrado. Estimulante, portanto! Seria essa a realidade da Toyota? Ou das milhares de fábricas que, à sua imagem e semelhança, estavam se reestruturando pelo mundo afora?

Nem o livro de Marx, nem as pesquisas, nem os sindicatos têm indicado essa realidade. O problema de fundo é que os grupos são montados como novidade, mas sua concepção, suas prerrogativas, sua estrutura e funcionamento continuam escorados em uma visão rasteira de autonomia, de responsabilidade e de produção estanque.

De fato, os grupos de extração toyotista estão centrados numa transferência parcial das atividades dos supervisores e gerentes para os próprios trabalhadores. Dessa forma, os work teams aproximar-se-iam de uma reunião de operários vivenciando uma agregação (mecânica) de responsabilidades, sem identidade coletiva. Não é à toa que muitos grupos são assim definidos apenas por (e para) incorporarem mecanismos de autosupervisão e vigilância mútua. $\mathrm{O}$ controle gerencial por meio do líder nomeado pela empresa, base da intensificação do ritmo de trabalho, possibilitaria o que Marx, baseando-se em Zarifian, caracterizou como um movimento de "retaylorização".

Work teams dessa natureza podem até servir como ponto de apoio para a construção de grupos semi-autônomos no interior de uma perspectiva de dinâmica organizacional, como aponta Marx. No entanto, claramente, um olhar desse tipo, ao detectar mais continuidade e permanência do que superação e ruptura com a matriz taylorista, diminui em muito o charme da lean production como um modelo superior.

Estruturas industriais voltadas para a qualificação sistemática dos trabalhadores, flexíveis o suficiente para utilizar a competência e a autonomia na produção, são difíceis de serem concebidas. Suas ocorrências ainda se revestem de caráter exploratório. Exigem desprendimento das empresas e disposição de quem trabalha, a começar pelos sindicatos.

A nova agenda que anunciam pede, no mínimo, uma reflexão de fundo sobre: (a) a necessidade de uma redistribuição do poder dentro da fábrica, (b) a viabilização de um sistema de aprendizagem e qualificação constante e (c) a vontade de compartilhar as definições estratégicas com os trabalhadores.

Esses são alguns dos pontos fundamentais - catalisadores de efetivas mudanças de visão e de postura das empresas - registrados por Marx em seu livro que podem estimular a reflexão e orientar a prática de todos os que pretendem implantar grupos semi-autônomos no Brasil.

Em nosso país, raríssimas foram as experiências que buscaram dar mais autonomia aos operários da produção ou tentaram estabelecer parâmetros para uma coparticipação e co-decisão no âmbito da empresa. Na raiz dessa dificuldade reside um atraso secular no que se refere ao grau de civilização de nossa sociedade, em que democracia e cidadania são bens quase supérfluos.

A discussão apresentada por Marx em seu livro pode nos ajudar a compreender e a diminuir o índice de teatralização que permeia o mundo do management $\mathrm{e}$ do universo fabril. 